\title{
DESCENDING BRANCH OF LATERAL FEMORAL CIRCUMFLEX ARTERY AS A FREE GRAFT FOR MYOCARDIAL REVASCULARIZATION: A CASE REPORT
}

Takahiko O. Tatsumi, MD, PhD, ${ }^{a}$ Yoshio Tanaka, MD, PhD, ${ }^{\mathrm{b}}$ Keiichiro Kondoh, MD, PhD, ${ }^{a}$ Seiichiro Minohara, MD, PhD, ${ }^{\text {a }}$ Yoshihide Sawada, MD, PhD, ${ }^{a}$ Takao Tsuchida, MD, ${ }^{\text {a }}$ Sadao Tajima, MD, PhD, ${ }^{\mathrm{b}}$ and Shinjiro Sasaki, MD, PhD, Osaka, Japan

The lateral femoral circumflex artery (LFCA) is one of the branches of the deep femoral artery. In the field of plastic and reconstructive surgery, the LFCA has been used to supply composite tissue of skin and/or muscle..$^{1-3}$ The LFCA has three major branches: the ascending, transverse, and descending branches. The descending branch of the LFCA passes downward through the intermuscular space between the rectus femoris muscle and the vastus lateralis muscle and finally terminates in the vastus muscle near the knee joint. The desceriding branches of the LFCA have a very large diameter ( 2 to $3 \mathrm{~mm}$ ) and do not taper like those of the radial arteries. ${ }^{3}$ The descending branch of the LFCA has an attractive caliber and length. We report the first case in which a descending branch of the LFCA was used as a graft for myocardial revascularization.

A 77-year-old woman had a 7-month history of increasing angina on exertion. Electrocardiographic changes were consistent with effort angina. Cardiac catheterization revealed a $99 \%$ stenosis of the proximal right coronary artery and a 75\% stenosis of the middle third of the left anterior descending coronary artery.

For this patient, we had planned to perform coronary artery bypass grafting (CABG): a left internal thoracic artery (LITA) in situ to the left anterior descending coronary artery and a saphenous vein graft to the right coronary artery. However, the saphenous vein had varices and was unacceptably thin. We also decided to avoid grafting the right internal thoracic artery to the right coronary artery for this elderly woman because devascularization of the sternum suggested a greater risk of sternal wound infections with the use of bilateral internal thoracic artery grafts. We concluded that the descending branch of the LFCA could be used to bypass the right coronary artery. We had evaluated the descending branches of the LFCA bilaterally by means of a femoral arteriogram 5 days before this operation. The arteriogram showed a good quality vessel without stenosis (Fig. 1).

The descending branch of the left LFCA was harvested

From the Departments of Thoracic Surgery a and Plastic and Reconstructive Surgery, ${ }^{\text {b }}$ Osaka Medical College, Osaka, Japan.

Received for publication Oct. 9, 1995; accepted for publication Oct. 27, 1995.

Address for reprints: Takahiko O. Tatsumi, MD, $\mathrm{PhD}$, O.M.C., 2-7 Daigakucho, Takatsuki, Osaka, 569 Japan.

J Thorac Cardiovasc Surg 1996;112:546-7

Copyright (C) 1996 by Mosby-Year Book, Inc.

$0022-5223 / 96 \$ 5.00+0 \quad \mathbf{1 2 / 5 4 / 7 0 3 3 0}$



Fig. 1. Preoperative femoral arteriogram showed that the descending branch of the LFCA was a good quality vessel without stenosis (arrows).

while the LITA was isolated. An incision of approximately $14 \mathrm{~cm}$ was made in the middle third of left thigh along the lateral margin of the left rectus femoris muscle. The descending branch of the LFCA courses between the rectus femoris muscle and the vastus lateralis muscle and was easily visualized when the rectus femoris muscle was retracted medially and the intermuscular space was explored. We carefully isolated a $13 \mathrm{~cm}$ graft. The outer and inner diameters of the distal portion of the descending branch of the LFCA were $2.0 \mathrm{~mm}$ and $1.5 \mathrm{~mm}$, respectively. The outer and inner diameters of the proximal portion of the descending branch the LFCA were $3.0 \mathrm{~mm}$ and $1.5 \mathrm{~mm}$, respectively. The size and quality of this descending branch of the LFCA were similar to those of the LITA in this case. 




Fig. 2. Postoperative angiogram showed that the descending branch of the LFCA bypass graft was patent (arrows).

CABG was performed per protocol. The distal portion of the descending branch of the LFCA was first anastomosed to the right coronary artery and the proximal portion to the ascending aorta. The distal portion of the LITA was then anastomosed to the left anterior descending artery. The flow rate within the descending branch of the LFCA graft was $40 \mathrm{ml} / \mathrm{min}$ when the patient was weaned from cardiopulmonary bypass.

The patient recovered without complications and regained full use of the left lower extremity. A postoperative coronary arteriogram of the descending branch of the LFCA and LITA grafts and native vessels was obtained at 30 days. This angiogram showed that the descending branch of the LFCA bypass graft was patent and functional (Fig. 2). Electrocardiography showed no ST change during exercise.
Several points regarding this use of the descending branch of the LFCA as a bypass graft can be addressed. With regard to the quality of the vessel, the descending branch of the LFCA of this particular patient, although thin, was similar in size to the LITA. With the free internal thoracic artery already applied as a graft, ${ }^{4}$ the free descending branch of the LFCA can be considered as an alternative. Moreover, the descending branch of the LFCA is readily accessible and easier to isolate than the internal thoracic artery, gastroepiploic artery, inferior epigastric artery, and radial artery. Last, inasmuch as the muscles of the thigh supplied by the descending branch of the LFCA have a rich collateral supply, functional deficits associated with the operation are potentially lessened. For these reasons, we believe that the descending branch of the LFCA shows promise as an autologous graft for $\mathrm{CABG}$.

We thank Michelle Zimmerman for help with manuscript preparation.

\section{REFERENCES}

1. Song YG, Chen GZ, Song YL. The free thigh flap: a new free flap concept based on the septocutaneous artery. Br J Plast Surg 1984;37:149-59.

2. Koshima I, Fukuda H, Yamamoto H, Moriguchi T, Sọeda S, Ohta S. Free anterolateral thigh flaps for reconstruction of head and neck defects. Plast Reconstr Surg 1993;92:421-8.

3. Koshima I, Kawada S, Etoh H, Kawamura S, Moriguchi T, Sonoh $\mathrm{H}$. Flow-through anterior thigh flaps for one-stage reconstruction of soft-tissue defects and revascularization of ischemic extremities. Plast Reconstr Surg 1995;95:252-60.

4. Loop FD, Lytle BW, Cosgrove DM, Golding LAR, Taylor PC, Stewart RW. Free (aorta-coronary) internal mammary artery graft. J Thorac Cardiovsc Surg 1986;92:827-31.

\title{
CYTOMEGALOVIRUS PNEUMONIA AFTER CARDIOVASCULAR OPERATIONS
}

\author{
N. Fukushima, MD, ${ }^{\text {a }}$ R. Shirakura, MD, ${ }^{\mathrm{a}}$ N. Taenaka, MD, ${ }^{\mathrm{b}} \mathrm{S}$. Nakano, MD, ${ }^{\mathrm{a}}$ and H. Matsuda, MD, ${ }^{\mathrm{a}}$ Osaka, Japan
}

Cytomegalovirus (CMV) has long been known to be fatal to immunocompromised patients. It has been widely recognized that patients undergoing cardiovascular oper-

From the First Department of Surgery, ${ }^{a}$ Department of Intensive

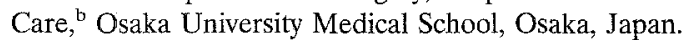

Received for publication Oct. 27, 1995; accepted for publication Oct. 30, 1995.

Address for reprints: Norihide Fukushima, MD, First Department of Surgery, Osaka University Medical School, 2-2 Yamada-Oka, Suita, Osaka 565, Japan.

J Thorac Cardiovase Surg 1996;112:547-8

Copyright $(\mathcal{C} 1996$ by Mosby-Year Book, Inc.

$0022-5223 / 96 \$ 5.00+0 \quad \mathbf{1 2} / \mathbf{5 4} / \mathbf{7 0 3 3 3}$ ations, especially open heart operations, are susceptible to CMV infection. ${ }^{1}$ The majority of these infections, however, are subclinical and only a small percent of these individuals have a more severe illness characterized by fever and liver injury. ${ }^{2}$ Thus CMV infection after cardiac operations has not been considered a serious disease for a long time. However, recent reports have emphasized that CMV infection after heart operations may be far more sinister. ${ }^{2,3}$ In this report, we describe two cases of multiple organ failure and CMV pneumonia after cardiovascular operation. We also discuss the methods of diagnosis and treatment for CMV infection.

CASE 1. A 47-year-old woman underwent open mitral commissurotomy and tricuspid annuloplasty. The CMV titer was 1:256 before the operation. She had aspiration 